\title{
Effect of Water Exchange Rate on Interspecies Competition Between Submerged Macrophytes: Functional Trait Hierarchy Drives Competition
}

\section{Duanyang Yuan \\ Yunnan University \\ Qihang Wu \\ Yunnan University \\ Lin Jin \\ Yunnan University \\ Mingli Xie \\ Yunnan University \\ Yang Gu \\ Yunnan University \\ Changqun Duan \\ Yunnan University}

Ying Pan ( $\sim$ py228@126.com )

Yunnan University https://orcid.org/0000-0002-1081-1574

\section{Research Article}

Keywords: Hydrological variation, plant competition, root morphology, stoichiometric characteristics, trait hierarchy, trait similarity

Posted Date: February 11th, 2021

DOl: https://doi.org/10.21203/rs.3.rs-201636/v1

License: (c) (1) This work is licensed under a Creative Commons Attribution 4.0 International License. Read Full License

Version of Record: A version of this preprint was published at Plant and Soil on July 16th, 2021. See the published version at https://doi.org/10.1007/s11104-021-05081-x. 


\section{Abstract}

Aims: Although the relative contributions of the "competition-trait similarity" and "competition-trait hierarchy" hypotheses in predicting competitive outcomes in response to environmental variation has recently been investigated in terrestrial plants, their validity in aquatic plants remain poorly understood, particularly in terms of variation in the water exchange rate (WER).

Methods: To this end, this study investigated the influence of WER variation on interspecies competition and functional traits in two pairs of submerged macrophytes (Vallisneria natans vs. Myriophyllum aquaticum and $V$. natans vs. Myriophyllum spicatum) under three levels of WER using the replacement series experiment.

Results: Results showed that $V$. natans was a stronger competitor than either Myriophyllum species in static waterbodies. However, the relative competitive ability of $V$. natans consistently decreased with increasing WER and decreasing its planting proportion, which would eventually change it from a stronger to weaker competitor. Between species pairs, most functional traits showed competently opposite patterns to increasing WER and decreasing the planting proportion of $V$. natans.

Conclusions: Our results indicate that WER affected the outcome of interspecies competition between submerged macrophyte species, and moreover, the relative competition ability of each species within a pair was linked strongly to species' competition-trait hierarchy than to competition-trait similarity.

\section{Highlights}

1. Interspecies competition of submerged plants to WER were analyzed.

2. WER altered outcome of interspecies competition between submerged plants.

3. CTH is more useful than CTS in predicting interspecies competition.

\section{Introduction}

Understanding how resource competition influences the relative abundance of plants is among the oldest pursuits in ecological research. According to the minimum resource requirement theory, species with lower demand will become dominant if all species use the same limiting resource (Tilman, 1980), whereas the maximum growth rate theory states that species with relatively higher growth rates (or greater ability to capture environmental nutrients) will displace the others (Grime, 1997). Functional traits (e.g., growth, survival, and physiological and morphological characteristics) determine the adaptive specialization, fitness, and persistence of species within a habitat (Kraft et al., 2015). Therefore, quantifying interspecific differences in functional traits is a promising approach for testing competition hypotheses in plants under different environmental conditions (Coomes \& Grubb, 2003).

With the development of trait-based approaches, the practicability of these two theories has been questioned. Instead, several trait-based theories relating resource competition and relative abundance of 
plants have been derived, such as the "competition-trait similarity" (CTS; Cahill et al., 2008) and "competition-trait hierarchy" hypotheses (CTH; Kunstler et al., 2012; Kraft et al., 2015). The CTS hypothesis assumes that competition is more intense among species with similar trait values because functional similarity is often associated with similar resource use. While, the CTH hypothesis states that functional dissimilarity (differences in traits directly associated with plant competitive ability and fitness) should favor particular competitors over others, i.e., competitive intensity is strong between species with different trait values. Although these contrasting hypotheses have been explored repeatedly in terrestrial plants under various environmental stresses, their applicability in aquatic macrophytes has yet not been investigated (Goldberg \& Novoplansky, 1997), particularly with respect to hydrological variation.

Hydrological variation caused by global climate change and the development of hydrological engineering works is a major threat to aquatic organisms, often leading to a pervasive loss of biodiversity and productivity declines (Hopkins et al., 1993; Good et al., 2009). Hydrological variation is particularly challenging for aquatic macrophytes because they cannot escape unfavorable environments (Pires et al., 2016). Among various hydrological elements, the water exchange rate (WER) directly influences various physical and chemical properties of the water column and sediments (Hopkins et al., 1993; Reitsema et al., 2020), and thus greatly impacts the growth and functional traits of aquatic macrophytes. Generally speaking, rapid water exchange can increase hydrodynamic forces and decrease water transparency, which will reduce the rooting and regeneration capacity of aquatic macrophytes, or even cause mechanical damage to plant organs (Zhu et al., 2012; Zhang et al., 2014). Conversely, slow water exchange generally reduces sediment nutrient release, and prevents the replenishment of dissolved oxygen (DO) and dissolved carbon dioxide (DCD) from incoming water and/or the air-water interface due to weakened flow turbulence (Jirka et al., 2010; Pan et al., 2019). These changes will further alter root and leaf traits that are strong associated with nutrients, as well as DO and DOC absorption (Pan et al., 2012; Hussner et al., 2016; Hessen et al., 2017).

These traits may have differential responses to WER variation among species that coexist in the same aquatic community owing to differences in species tolerance thresholds. For example, our previous studies have found that separately cultured submerged macrophytes Hydrilla verticillata and Myriophyllum aquaticum exhibited similar response patterns when subjected to increasing WER; however, these adjustments were greater in $M$. aquaticum than in $H$. verticillate, resulting in a more dramatic increase of plant biomass in M. aquaticum (Yuan et al., 2018). Similar links between hierarchical traits and plant fitness to hydrological variation have been observed in various wetland species (Pan et al., 2012; Pan et al., 2019). Thus, functional differences may favor some competitors over others, such that CTH may play a more important role than CTS in explaining the outcome of interspecies competition for aquatic macrophytes. Understanding how functional traits vary with WER is of primary importance to verify the valid of the CTS and CTH hypotheses, and to predict future changes in aquatic plant communities (Wang et al., 2010).

The object of this study is to test the theoretical links between functional traits and interspecies competition in submerged macrophytes under the stress of WER variation. We conducted two laboratory 
experiments (a schematic of the experimental device is presented in Figure S1) to examine the effects of varying WER $\left(0 \%, 20 \%, 40 \%\right.$ of total volume day $\left.^{-1}\right)$ on environmental conditions (DO and DCD concentrations) in the absence of plants, and plant functional dissimilarity (i.e., morphological characteristics, and carbon [C], nitrogen [N], and phosphorus [P] stoichiometry) and relative competitive ability in two coexisting pairs of submerged macrophytes: Vallisneria natans vs. M. aquaticum and $V$. natans vs. Myriophyllum spicatum. $V$. natans and $M$. spicatum are common vegetation components of freshwater lakes throughout the world (Cao et al., 2011). While, M. aquaticum is an invasive species native to South America that has spread throughout many countries, including in lakes of the Yunnan Province, China (You et al., 2013). The following were addressed: (1) to investigate whether WER could induce interspecific differences in functional traits and thus affect interspecies competition; (2) to verify the valid of the CTS and CTH hypotheses in predicting the outcome of interspecies competition between these co-cultured submerged species. We hypothesized that relative competition ability in the submerged macrophyte pairs would be positively related to the hierarchical difference in their functional traits.

\section{Materials And Methods}

\section{Experimental material}

Three species of aquatic macrophytes were used in this experiment: $V$. natans, $M$. aquaticum, and $M$. spicatum. V. natans is ubiquitous in aquatic ecosystems, regardless of hydrological condition (Zhu et al., 2018a). Both Myriophyllum species can become dominant species only in areas with strong hydrodynamic forces. For example, M. aquaticum tends to distribute in lakeshore zones strongly affected by waves, and $M$. spicatum is more frequently found in inlet and outlet channels, and regions with strong wind and fast WER (Wersal \& Madsen, 2011; Zhu et al., 2018b).

All samples of the three aquatic macrophytes were collected in April 2018 from Shaping Bay $\left(25^{\circ} 56^{\prime} \mathrm{N}\right.$, $100^{\circ} 6^{\prime} \mathrm{E}$ ), east of Erhai Lake, Yunnan Province, China. Lake sediment (containing $0.16 \mathrm{~g} \mathrm{~kg}^{-1}$ total N and $1.69 \mathrm{~g} \mathrm{~kg}^{-1}$ total P) was collected simultaneously in these sites as experimental sediment. All ramets collected were planted in plastic buckets $(67 \mathrm{~cm} \times 45 \mathrm{~cm} \times 55 \mathrm{~cm}$; filled with $10 \mathrm{~cm}$ lake sediment and 20 $\mathrm{cm}$ tap water) in a greenhouse at Yunnan University for pre-culturing, where they sprouted new ramets.

\section{Experimental design}

Three water exchange rates, i.e., statistic water ( $0 \%$ replacement of the whole water body per day), medium WER (20\%), and high WER (40\%) were applied. This range of WER variation is reasonable for natural ecosystems (including Erhai Lake) according to our previous studies (e.g., Yuan et al., 2018). Two replacement series (of $V$. natans vs. M. aquaticum and $V$. natans vs. M. spicatum) were performed to increase the universality of our findings. Five combination modes (ratio of $V$. natans numbers to those of corresponding Myriophyllum species of 8: 0, 6:2, 4: 4, 2: 6, and 0: 8) were used for each replacement series as a standard replacement experiment (Connolly, 1986; Gibson et al., 1999). 
Collectively, a total of 30 treatments (three WERs $\times$ two replacement series $\times$ five combination modes) were designed; each treatment had five replicates. Each replicate was a plastic pot $(20-\mathrm{cm}$ in height and $35-\mathrm{cm}$ in diameter); a total of 150 pots were transported to 30 buckets $(100 \mathrm{~cm} \times 60 \mathrm{~cm} \times 50 \mathrm{~cm}$, approximately $300 \mathrm{~L}$ ) before the experiment. Ten buckets were applied to each of the three WER levels, and each bucket contained five plots of different combination modes belonging to the same replacement series. Collectively, a total of $600 \mathrm{~V}$. natans ramets and 300 of each Myriophyllum species of a similar size (length [mean $\pm S D, n>150$ ]: $5.36 \pm 0.43 \mathrm{~cm}$ for $V$. natans, $7.23 \pm 0.41 \mathrm{~cm}$ for $M$. aquaticum, and 7.21 $\pm 0.47 \mathrm{~cm}$ for $M$. spicatum) were used in the experiments. The bottom of each pot was enclosed with nylon net and filled with $10 \mathrm{~cm}$ of the same sediment as that used for plant incubation.

The main experiment was conducted in the same greenhouse on June 1, 2018, during a period of 50 days. Tap water was first aerated with sterile filtered air (Sartorius, Midisart 2000) in an aeration tank to homogenize DO and DCD, and then supplied to each WER treatment as needed throughout the experiment. An additional three-day experiment was conducted before the start of the main experiment to investigate indicator (DO and DCD) differences between incoming water and bucket water in the absence of ramets (see Table S1).

\section{Experiment in the absence of ramets}

To accurately estimate the effects of the WER on water properties, an additional experiment without ramets was set up for each of the treatments to accurately estimate the effects of WER on water properties without the interference of submerged ramets. Each treatment contained three buckets.

DO and DCD concentrations of the system water were measured on days $1,3,5,7,9,11,13$, and 15 at a depth of $45 \mathrm{~cm}$ (10 cm above the pot bottom) during the daytime (12:00-14:00) and night (22:0024:00). The DO and DCD concentrations were determined using a DO meter (HQ40d, Hach, Loveland, USA), and a DCD meter (AMT-SC200, Shenzheng Yunchuan Wulian Technologies Co. Ltd, Shenzheng, China), respectively.

\section{Experiment in the presence of ramets}

At the end of the experiment, plant height was recorded as the distance between the ground surface and leaf tip. The branch number of newly developing ramet was recorded for each plant. Only $V$. natans plants produced new ramets throughout this experiment. Subsequently, plants were carefully removed from the sediment to maintain intact root systems, and rinsed with tap water. Plants were divided into the aboveground (leaves for $V$. natans, and leaves and stems for two Myriophyllum species) and below-ground parts (roots, stolons and rhizomes for all three species), and then the fresh biomass of each part was weighed using an electronic analytical balance (AX224ZH/E, Ohaus, Florham Park, NJ, USA; sensitivity $0.0001 \mathrm{~g})$.

Fresh roots were used for root morphological analyses. At least three representative fully grown adventitious roots (growing from rhizomes and below the sediment surface) were selected from each ramet, and the mean root length and diameter were measured using a Vernier caliper and a microscope 
equipped with an ocular micrometer (Olympus BX51; Olympus, Japan), respectively. The total root length and fresh weight of the three adventitious roots (cut from lateral roots) were recorded for each plant, and specific root length (SRL) was defined as total root length divided by fresh root mass. Values of mean root length, diameter and SRL of each plant species were first averaged for each pot, and then for each treatment.

The remaining tissues of each plant were dried at $85^{\circ} \mathrm{C}$ for $48 \mathrm{~h}$ and weighed to determine the wet to dry conversion factor. Then the dry weights were used to calculate the below-ground to above-ground (B:A) biomass ratio, biomass accumulation, and branch number per plant mass. Biomass accumulation was calculated as the sum of the above-ground and below-ground tissue biomass. Branch number per plant mass was calculated as branch number divided by total biomass of the stock plant (not including the biomass of newly developing ramets). Finally, plant parts in each treatment were ground into powder and mixed together to measure nutrient components. Samples were digested with $\mathrm{H}_{2} \mathrm{SO}_{4}-\mathrm{H}_{2} \mathrm{O}_{2}$ and evaluated for $\mathrm{P}$ and $\mathrm{N}$ contents per plant using colorimetric analyses (Xie et al., 2005). Organic $\mathrm{C}$, which usually occupies the vast majority of total $\mathrm{C}$ in plants, was measured using the $\mathrm{K}_{2} \mathrm{Cr}_{2} \mathrm{O}_{7}$ oxidation procedure ( $\mathrm{Lu}$, 2000). The $C: N, C: P$, and N:P ratios of each plant were calculated from the total $P$, total $N$, and organic $C$ results obtained.

We also used three competition indexes to investigate the strength of competition between co-cultured species in each replacement series: relative yield (RY), total relative yield $\left(R Y_{T}\right)$, and aggressivity $(A)$. $R Y$ for $V$. natans $\left(\mathrm{RY}_{\mathrm{V}}\right)$ and Myriophyllum species $\left(\mathrm{RY}_{\mathrm{M}}\right)$ were calculated from the dry weight of each sample for different treatments, according to the following equations (Bi \& Turvey, 1994; Burnett \& Mealor, 2015):

$$
\begin{array}{ll}
\mathrm{RY}_{\mathrm{V}} & =P_{\mathrm{V}} \times \frac{V_{\min }}{V_{\operatorname{mon}}} \\
\mathrm{RY}_{\mathrm{M}} & =P_{\mathrm{M}} \times \frac{M_{\min }}{M_{\operatorname{mon}}}
\end{array}
$$

where $P_{\mathrm{V}}$ and $P_{\mathrm{M}}$ are the proportions of $V$. natans and Myriophyllum species in the mixture for each replacement series. $V_{\text {mix }}$ and $V_{\text {mon }}$ are the mean biomass accumulation of $V$. natans in mixture and monoculture, respectively. $M_{\text {mix }}$ and $M_{\text {mon }}$ are the mean biomass of the corresponding Myriophyllum species in mixture and monoculture, respectively.

$R Y_{T}$ was calculated according to the following equation (De Wit, 1960; Bi \& Turvey, 1994):

$$
\mathrm{RY}_{\mathrm{T}}=\mathrm{RY}_{\mathrm{V}}+\mathrm{RY}_{\mathrm{M}}
$$

(equation 3)

$R Y_{T}$ can be used to predict species interaction between co-cultured species. $R Y_{T}<1$ indicates that the intensity of interspecific competition is greater than that of intraspecific competition (i.e., both species compete for the same environmental resource); $R Y_{T}=1$ indicates that the intensity of interspecific 
competition is equal to that of intraspecific competition, and $R Y_{T}>1$ indicates that the intensity of interspecific competition is lower than that of intraspecific competition (i.e., both species compete for different environmental resources) (Bi \& Turvey, 1994).

A is a useful indicator of the relative competitive ability of two co-cultured plant species (Willey, 1979). For $V$. natans, $A_{V}$ was calculated according to the following equation (Dhima et al., 2007):

$$
\mathrm{A}_{\mathrm{V}}=0.5\left[\frac{V_{\text {mix }}}{V_{\mathrm{mon}}}-\frac{M_{\text {mix }}}{M_{\mathrm{mon}}}\right]
$$

Values of $A_{V}=0$ indicates that the competitive ability of $V$. natans was equal to those of Myriophyllum species; $A_{V}<0$ indicates that the competitive ability of $V$. natans is lower than that of Myriophyllum species; and $A v>0$ indicates that the competitive ability of $V$. natans is greater than that of Myriophyllum species.

\section{Statistical analyses}

In the experiment without ramet addition, we used one-way repeated measures analysis of variance (ANOVA) followed by a Bonferroni post hoc test to test the effects of WER on waterbody variables (DCD and DO concentrations in the bucket water) for each observation time.

In the experiment containing ramets, two-way and three-way ANOVAs followed by the Tukey test were performed to determine the effects of WER, combination mode, and/or plant species on plant characteristics in each replacement series, including biomass, plant height, B:A biomass ratio, root morphology, branch number per plant biomass, and plant nutrient contents. One-way ANOVA followed by the Tukey test was performed to determine the effects of WER on three competition indexes.

Besides, linear regression analyses were conducted to determine the relationships among waterbody variables, growth, plant morphological characteristics, and plant nutrient status. All data were tested for normality and variance homogeneity before analyses. Data for SRL, below: above-ground biomass ratio, and plant height were $\log _{10}$-transformed to meet the assumptions of homogeneity and normality of variance prior to one-way ANOVA. All statistical analyses were performed using the SPSS 25.0 software (SPSS Inc., Chicago, IL, USA).

\section{Results}

\section{Environmental variables in the absence of ramets}

DCD concentration was significantly lower, and DO concentration was higher in incoming water than in the experimental waterbodies $(P<0.05 ;$ Table S1). As a result, DO concentration significantly increased $(P$ $<0.001$; Fig. 1a,b; Table S2), whereas DCD concentration sharply decreased as WER increased through the whole experiment in the daytime and nighttime ( $P<0.001$; Fig. $1 \mathrm{c}, \mathrm{d}$; Table S2). Throughout the 
experimental period, DCD concentration ranged from 356 to 488 ppm, and DO concentration was always larger than $6.0 \mathrm{mg} \mathrm{L}^{-1}$.

\section{Plant biomass, height and biomass allocation}

Three-way ANOVA results indicated that plant biomass, height, and biomass allocation (B:A biomass ratio) were significantly affected by WER and plant species $(P<0.01)$, while, the effects of combination mode on these three variables were dependent on plant species, with significant plant species $x$ combination mode interactions $(P<0.001)$, regardless of the competition system (Tables 1 and 2 ).

Table 1

Summary of the three-way ANOVAs determining effects of plant species (Vallisneria natans and Myriophyllum aquaticum), water exchange rate (WER), and combination mode (CM) on plant biomass, plant height, below: above-ground biomass ratio (B: A biomass ratio), root length, specific root length

(SRL), root diameter, plant C, plant $\mathrm{N}$ and plant $\mathrm{P}$ in $\mathrm{V}$. natans - M. aquaticum system.

\begin{tabular}{|c|c|c|c|c|c|c|c|}
\hline & $\begin{array}{l}\text { Species } \\
(S, d f=1)\end{array}$ & $\begin{array}{l}\text { WER } \\
(W ; d f= \\
2)\end{array}$ & $\begin{array}{l}\text { CM } \\
(C, d f \\
=4)\end{array}$ & $S \times W$ & $S \times C$ & $W \times C$ & $\begin{array}{l}S \times W \\
\times C\end{array}$ \\
\hline $\begin{array}{l}\text { Biomass (g } \\
\text { dry wt plant } \\
\text { 1) }\end{array}$ & $241.070^{\star \star \star}$ & $26.467^{\star \star \star}$ & 0.861 & $205.408^{\star \star \star}$ & $72.893^{\star \star \star}$ & 1.181 & 0.610 \\
\hline $\begin{array}{l}\text { Plant height } \\
(\mathrm{cm})\end{array}$ & $12.780^{\star \star}$ & $55.483^{\star \star \star}$ & 2.432 & $335.826^{\star * *}$ & $96.011^{\star * *}$ & 1.437 & $2.250^{*}$ \\
\hline $\begin{array}{l}\text { B:A biomass } \\
\text { ratio }\end{array}$ & $31.078^{\star \star \star}$ & $17.266^{\star \star \star}$ & 0.880 & $490.162^{\star \star \star}$ & $289.472^{\star \star \star}$ & 1.622 & 2.156 \\
\hline $\begin{array}{l}\text { Root length } \\
(\mathrm{cm})\end{array}$ & $51.877^{\star \star \star}$ & $47.269^{\star \star \star}$ & 2.293 & $318.072^{\star \star \star}$ & 135.139 & $12.530^{\star \star \star}$ & 1.355 \\
\hline $\begin{array}{l}\mathrm{SRL}\left(\mathrm{m} \mathrm{g}^{-1}\right. \\
\text { fresh wt) }\end{array}$ & $94.079^{\star * \star}$ & $5.728^{\star \star}$ & $6.418^{\star *}$ & $53.532^{\star \star \star}$ & $142.444^{\star \star \star}$ & 0.653 & $2.725^{\star}$ \\
\hline $\begin{array}{l}\text { Root diameter } \\
\text { (um) }\end{array}$ & 0.079 & $5.509^{* *}$ & $3.411^{*}$ & $111.219^{\star \star \star}$ & $36.347^{\star \star \star}$ & 0.904 & $4.584^{\star \star}$ \\
\hline $\mathrm{C}\left(\mathrm{mg} \mathrm{g}^{-1}\right)$ & 2.189 & 1.523 & 0.894 & $13.430 * \star \star$ & $4.427 \star \star$ & 1.803 & 1.002 \\
\hline $\mathrm{N}\left(\mathrm{mg} \mathrm{g}^{-1}\right)$ & 2.387 & $67.068^{\star \star \star}$ & 0.497 & 1.598 & $9.170^{\star \star \star}$ & 0.551 & 0.356 \\
\hline$P\left(\mathrm{mg} \mathrm{g}^{-1}\right)$ & 2.544 & 0.707 & 2.033 & $35.738^{\star \star \star}$ & $78.497^{\star \star \star}$ & 0.843 & 0.460 \\
\hline
\end{tabular}


Table 2

Summary of the three-way ANOVAs determining effects of plant species (Vallisneria natans and Myriophyllum spicatum), water exchange rate (WER), and combination mode (CM) on plant biomass, plant length, below: above-ground biomass ratio (B: A biomass ratio), root length, specific root length, root diameter, plant $\mathrm{C}$, plant $\mathrm{N}$ and plant $\mathrm{P}$ in $\mathrm{V}$. natans - M. spicatum system.

\begin{tabular}{|c|c|c|c|c|c|c|c|}
\hline B & $\begin{array}{l}\text { Species } \\
(S, d f=1)\end{array}$ & $\begin{array}{l}\text { WER } \\
(W ; d f=2)\end{array}$ & $\begin{array}{l}\text { CM } \\
(C, d f \\
=4)\end{array}$ & $S \times W$ & $S \times C$ & $W \times C$ & $S \times W \times$ \\
\hline $\begin{array}{l}\text { Biomass (g } \\
\text { dry wt plant }{ }^{-} \\
{ }^{1} \text { ) }\end{array}$ & $51.131^{\star \star \star}$ & $15.517^{\star \star \star}$ & 1.080 & $236.563^{\star \star \star}$ & $136.130^{\star \star \star}$ & $2.852^{*}$ & 0.713 \\
\hline $\begin{array}{l}\text { Plant height } \\
\text { (cm) }\end{array}$ & $5380.696^{\star \star \star}$ & $73.580^{\star \star \star}$ & 2.353 & $370.947^{\star \star \star}$ & $23.383^{\star \star \star}$ & 1.771 & 0.905 \\
\hline $\begin{array}{l}\text { B:A biomass } \\
\text { ratio }\end{array}$ & $34.163^{\star \star \star}$ & $5.492^{\star *}$ & 2.063 & $17.042^{\star \star \star}$ & $30.664^{\star \star \star}$ & 0.562 & 1.404 \\
\hline $\begin{array}{l}\text { Root length } \\
\text { (cm) }\end{array}$ & $573.931^{\star \star \star}$ & $11.349^{\star \star \star}$ & 1.095 & $699.913^{\star \star \star}$ & $115.012^{\star \star \star}$ & 1.504 & $7.301^{\star \star \star}$ \\
\hline $\begin{array}{l}\operatorname{SRL}\left(\mathrm{m} \mathrm{g}^{-1}\right. \\
\text { fresh wt) }\end{array}$ & $2068.652^{\star \star \star}$ & $47.554^{\star \star \star}$ & 1.074 & $173.030^{\star \star \star}$ & $312.123^{\star \star \star}$ & 2.057 & 0.971 \\
\hline $\begin{array}{l}\text { Root } \\
\text { diameter } \\
\mathrm{r}(u \mathrm{~m})\end{array}$ & $1099.865^{\star \star \star}$ & 1.340 & 0.622 & $126.118^{\star \star \star}$ & $99.856^{\star \star \star}$ & $5.461^{\star \star \star}$ & 1.553 \\
\hline$C\left(\mathrm{mg} \mathrm{g}^{-1}\right)$ & 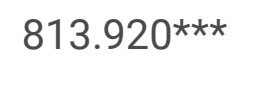 & $4.630 *$ & 0.560 & 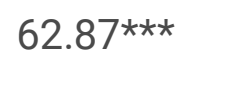 & $59.93^{\star \star \star}$ & 1.120 & 0.370 \\
\hline $\mathrm{N}\left(\mathrm{mg} \mathrm{g}^{-1}\right)$ & $11.395^{\star *}$ & $133.838^{\star \star \star}$ & 0.131 & 2.817 & 1.718 & 1.228 & 1.537 \\
\hline$P\left(\mathrm{mg} \mathrm{g}^{-1}\right)$ & $86.772^{\star \star \star}$ & 1.370 & 0.323 & $41.623^{\star \star \star}$ & $20.213^{\star \star \star}$ & 1.418 & 1.041 \\
\hline
\end{tabular}

Specifically, WER showed opposite effects on growth of co-cultured species, which led to decreases in plant biomass and height in $V$. natans, but increases in these variables in co-cultured Myriophyllum species as WER increased, regardless of the competition system $(P<0.001$; Fig. 2a, c, e, g, Tables S3 and S4). For example, at the end of the experiment, the plant biomass of $V$. natans decreased by $31.62 \%$, $39.11 \%, 37.16 \%$, and $34.81 \%$ in the $V$. natans - M. aquaticum system, and by $32.95 \%, 30.48 \%, 25.61 \%$, and $26.51 \%$ in the $V$. natans - $M$. spicatum system, in 8:0, 6:2, 4:4 and 2:6 combination mode from control to high WER, respectively. While, plant biomass increased by $37.03 \%, 24.91 \%, 16.80 \%$, and $23.43 \%$ for $M$. aquaticum, and by $43.61 \%, 45.87 \%, 39.80 \%$, and $40.48 \%$ for $M$. spicatum in $6: 2,4: 4,2: 6$ and $0: 8$ combination mode under the same conditions. Thus, higher WER clearly promoted the relative competitive ability of Myriophyllum species in co-cultured systems.

B:A biomass ratio and branch number per plant biomass also showed significant different responses to WER between co-cultured plant species ( $P<0.001$; Tables S3 and S4). For $V$. natans, both B:A biomass 
ratio (Fig. 3a,c) and branch number per plant biomass (Fig. 3e,f) increased with increasing WER, regardless of the competition system $(P<0.001$; Tables S3 and S4). By contrast, the B:A biomass ratio of Myriophyllum species generally decreased as WER increased, reaching a significant difference in the $V$. natans - $M$. aquaticum system ( $P<0.001$; Fig. 3b, Table S3). Neither Myriophyllum species allocated biomass to produce new ramets (i.e., branch formation) throughout the present study.

The effects of combination mode on these parameters showed similar patterns between co-cultured species, leading to decreases in species biomass and height, but increases in B:A ratio with decreasing its planting proportion ( $P<0.001$; Tables S3 and S4). Collectively, as WER increased and the planting proportion of $V$. natans decreased, the relative competitive ability of $V$. natans gradually decreased; meanwhile the B:A biomass ratio and branch number per plant biomass responses showed opposite patterns between co-cultured species under the same condition, regardless of the competition system.

Additionally, plant biomass and height were significantly and positively correlated with DCD concentration for $V$. natans, but negatively associated with DCD concentration for Myriophyllum species, particularly for $V$. natans, which reached a significance level regardless of competition system $\left(R^{2}>0.33\right.$; $P \leq 0.05$; Figures S2 and S3). While, B:A biomass ratio was generally negatively associated with DCD concentration for $V$. natans, but positively associated with DCD concentration for Myriophyllum species, particularly for $V$. natans in $V$. natans - $M$. aquaticum system $\left(R^{2}>0.53 ; P<0.01\right.$; Figures S4 and S5).

\section{Morphological characteristics}

Three-way ANOVA results indicated that root length and SRL were significantly affected by WER and species, regardless of the competition system $(P<0.01$; Tables 1 and 2$)$, whereas the effects of combination mode had significant effects on these parameters only in the $V$. natans $-M$. aquaticum system $(P<0.01$; Table 1$)$. Root diameter was significantly affected by both WER and combination mode in the $V$. natans $-M$. aquaticum system $(P<0.05$; Table 1$)$, but in the $V$. natans $-M$. spicatum system, the effects of WER and combination mode on root diameter were dependent on plant species, with significant plant species $\times$ combination mode, and plant species $\times$ WER interactions $(P<0.001$; Table 2$)$.

Similarly, WER had opposite effects on these morphological characteristics between co-cultured species. As WER increased, root length and SRL decreased, and root diameter increased in $V$. natans, regardless of the competition system ( $P<0.001$; Fig. 4a,c,e,g,i,k; Tables S3 and S4), but the opposite effect was observed in all three parameters among co-cultured Myriophyllum species $(P<0.001$; Fig. 4b,d,f,h,j, ; Tables S3 and S4). The effects of combination mode on these parameters showed similar patterns between co-cultured species, such as decreased root length and SRL, and increased root diameter as species planting proportion decreased $(P<0.001$; Tables S3 and S4). Collectively, as WER increased and the planting proportion of $V$. natans deceased, morphological characteristics showed opposite patterns between co-cultured species, regardless of the competition system.

Root length and SRL were generally positively correlated with DCD concentration for $V$. natans, but negatively associated with DCD concentration for Myriophyllum species, regardless of the competition 
system (Figure S4 and S5). For example, daytime DCD concentration exhibited significant relationships with root length for both co-cultured species and with SRL for $M$. spicatum in the $V$. natans - M. spicatum system $\left(R^{2}>0.43 ; P<0.05 ;\right.$ Figure $\left.S 4\right)$. By contrast, root diameter was significantly and negatively correlated with $D C D$ concentration for $V$. natans, but positively associated with DCD concentration for Myriophyllum species, regardless of the competition system and observation time $\left(R^{2}>0.37 ; P<0.05\right.$; Figures S4 and S5). Besides, all three parameters were significantly associated with plant biomass $\left(R^{2}>\right.$ $0.48 ; P<0.05$; Figure $S 6)$.

\section{Plant nutrients}

Three-way ANOVA results indicated that $\mathrm{N}$ content in plants was significantly affected by WER in both competition systems $(P<0.01$; Tables 1 and 2$)$, whereas the effects of WER on $P$ content were dependent on species, with a significant plant species $\times$ WER interaction $(P<0.001$; Tables 1 and 2$)$. Plant $\mathrm{C}$ content was significantly affected by WER, plant species, and their interaction in the $V$. natans $-M$. spicatum system $(P<0.05$; Table 2), but was only affected by the interactive effects between WER and plant species, and between combination mode and plant species in the $V$. natans - M. aquaticum system $(P<$ 0.01 ; Table 1). Species nutrients were unaffected by the individual effect of the combination mode, regardless of the competition system $(P>0.05$; Tables 1 and 2$)$.

Nutrient status responses to WER differed among nutrients and species. Concentrations of both $\mathrm{C}$ and $\mathrm{P}$ gradually decreased in $V$. natans, but increased in co-cultured Myriophyllum species as WER increased ( $P$ $<0.05$; Fig. 5; Tables S5 and S6). Plant $\mathrm{N}$ concentration significantly increased as WER increased in both co-cultured species, regardless of the competition system $(P<0.001$; Tables S5 and S6). As a result, the C: $\mathrm{N}$ ratio decreased, whereas the N: $\mathrm{P}$ ratio increased with increasing WER, regardless of the species and competition system ( $P<0.001$; Tables S5 and S6; Figure S7). N: P ratios were far below 14 throughout the experiment, regardless of the species and competition system.

Combination mode generally has similar effects on the nutrient status of co-cultured species. In the $V$. natans - $M$. aquaticum system, decreases in species planting proportions led to significant decreases in $\mathrm{N}$ and $\mathrm{P}$ concentrations $(P<0.05$; Table S5), but had not significant effect on $\mathrm{C}$ concentration $(P>0.05)$. As a result, $\mathrm{C}: \mathrm{N}$, and $\mathrm{C}: \mathrm{P}$ ratios consistently increased as the species planting proportion decreased $(P<$ 0.05; Figure S7; Table S5). In the V. natans - $M$. spicatum system, $C$ and $P$ concentrations were significantly affected by combination mode, which sharply decreased as species planting proportions decreased $(P<0.01 ;$ Table S6).

These results suggest that as WER increases and the planting proportion of $V$. natans decreases, $V$. natans will gradually be limited by nutrients, and the opposite effect would occur in co-cultured Myriophyllum species. Accordingly, the relationships between $\mathrm{N}$ concentration with plant biomass and plant morphological characteristics showed completely opposite patterns among co-cultured species. Specifically, $\mathrm{N}$ concentration was negatively associated with plant biomass, SRL, and root length, but positively associated with B:A ratio and root diameter in $V$. natans, regardless of the competition system; the opposite pattern was observed in co-cultured Myriophyllum species, with significant relationships of 
$\mathrm{N}$ with plant height and SRL in Myriophyllum species $\left(R^{2}>0.41 ; P<0.01 ;\right.$ Figure S9). However, $\mathrm{C}$ and $\mathrm{P}$ concentrations were generally positively associated with root length, $S R L$, and plant biomass, but negatively associated with B:A biomass ratio and root diameter, regardless of species (Figures S8 and S10).

\section{Interspecies interaction}

Three-way ANOVA results indicated that RY significantly differed between competition systems $(P<0.01$; Table S7), and the effects of WER on RYv and $R Y_{T}$ were dependent on the competition system, with significant competition system $\times$ WER interactions $\left(P<0.01\right.$; Table S7). $A_{V}$ was affected by combination mode $(P<0.001)$, and the interaction of combination mode and competition system $(P<0.05)$.

In the $V$. natans $-M$. aquaticum system, $\mathrm{RY}_{V}$ and $A_{V}$ significantly decreased as the planting proportion of $V$. natans decreased and as WER increased throughout the experiment $(P<0.05$; Table S8), with a significant combination mode $\times$ WER interaction $(P<0.05$; Tables 3 and 5). Notably, in the 6: 2 combination mode, the decreasing trends of these two variables became significant as WER increased $(P$ $<0.05$; Tables 3 and 5), indicating that the relative competitive ability of $V$. natans consistently decreased under this circumstance. In the $V$. natans - $M$. spicatum system, $\mathrm{RY}_{\mathrm{M}}$ and $\mathrm{RY} \mathrm{Y}_{\mathrm{T}}$ were significantly affected by both WER and combination mode $(P<0.05$; Table S8), which generally increased as WER increased from the whole experiment (Tables 3 and 4). Finally, as WER increased and the planting proportion of $V$. natans decreased, $A_{v}$ gradually deceased, from positive values in the $6: 2$ combination mode to negative values in the 2:6 combination mode. These results suggest that the relative competitive ability of $V$. natans gradually decreased as WER increased and its planting proportion decreased, eventually changing from a stronger to weaker competitor. Moreover, throughout the experiment, $R Y_{T}$ was always $<1$, regardless of the competition system, indicating that the intensity of interspecific competition was greater than that of intraspecific competition in our experiment (Table 4). 
Table 3

Results of one-way ANOVA showing the effects of water exchange rate (WER) on relative yield (RY) values in these two competing systems.

\begin{tabular}{|c|c|c|c|c|}
\hline \multirow[t]{2}{*}{ WER } & \multicolumn{3}{|c|}{ Density ratio of Vallisneria natans. Myriophyllum species } & \\
\hline & $6: 2$ & $4: 4$ & $2: 6$ & \\
\hline \multicolumn{5}{|c|}{ V. natans- $M$. aquaticum system } \\
\hline \multirow[t]{3}{*}{ V. natans } & 0 & $0.68 \pm 0.03 a$ & $0.42 \pm 0.02 c$ & $0.19 \pm 0.01 d$ \\
\hline & $20 \%$ & $0.62 \pm 0.02 b$ & $0.38 \pm 0.04 c$ & $0.19 \pm 0.02 d$ \\
\hline & $40 \%$ & $0.61 \pm 0.01 b$ & $0.39 \pm 0.01 \mathrm{c}$ & $0.18 \pm 0 d$ \\
\hline \multirow[t]{3}{*}{ M. aquaticum } & 0 & $0.15 \pm 0.04 c$ & $0.41 \pm 0.09 b$ & $0.72 \pm 0.05 a$ \\
\hline & $20 \%$ & $0.18 \pm 0.02 c$ & $0.4 \pm 0.06 b$ & $0.67 \pm 0.04 a$ \\
\hline & $40 \%$ & $0.18 \pm 0.01 \mathrm{c}$ & $0.42 \pm 0.02 b$ & $0.66 \pm 0.04 a$ \\
\hline \multicolumn{5}{|c|}{ V. natans- M. spicatum system } \\
\hline \multirow[t]{3}{*}{ V. natans } & 0 & $0.63 \pm 0.03 a$ & $0.35 \pm 0.05 b$ & $0.15 \pm 0.01 \mathrm{c}$ \\
\hline & $20 \%$ & $0.63 \pm 0.05 a$ & $0.37 \pm 0.03 b$ & $0.17 \pm 0.01 c$ \\
\hline & $40 \%$ & $0.66 \pm 0.06 a$ & $0.39 \pm 0.02 b$ & $0.17 \pm 0.02 c$ \\
\hline \multirow[t]{3}{*}{ M. spicatum } & 0 & $0.15 \pm 0.02 c$ & $0.34 \pm 0.06 b$ & $0.65 \pm 0.04 a$ \\
\hline & $20 \%$ & $0.16 \pm 0.03 c$ & $0.4 \pm 0.04 b$ & $0.7 \pm 0.04 a$ \\
\hline & $40 \%$ & $0.16 \pm 0.02 c$ & $0.37 \pm 0.04 b$ & $0.64 \pm 0.03 a$ \\
\hline
\end{tabular}

Table 4

Results of one-way ANOVA showing the effects of water exchange rate (WER) on total relative yield (RY $)$ values for total biomass in these two competing systems.

\begin{tabular}{|lllll|}
\hline & WER & \multicolumn{4}{l}{ Density ratio of Vallisneria natans. Myriophyllum species } \\
\cline { 3 - 5 } & & $\mathbf{6 : 2}$ & $4: 4$ & $2: 6$ \\
\hline V. natans - M. aquaticum system & 0 & $0.83 \pm 0.08 \mathrm{ab}$ & $0.83 \pm 0.11 \mathrm{ab}$ & $0.91 \pm 0.06 \mathrm{a}$ \\
& $20 \%$ & $0.80 \pm 0.02 \mathrm{ab}$ & $0.78 \pm 0.07 \mathrm{~b}$ & $0.86 \pm 0.05 \mathrm{ab}$ \\
\hline V. natans - M. spicatum system & 0 & $0.78 \pm 0.03 \mathrm{ab}$ & $0.69 \pm 0.08 \mathrm{c}$ & $0.80 \pm 0.04 \mathrm{ab}$ \\
& $40 \%$ & $0.79 \pm 0.02 \mathrm{ab}$ & $0.81 \pm 0.03 \mathrm{ab}$ & $0.84 \pm 0.04 \mathrm{ab}$ \\
& $20 \%$ & $0.79 \pm 0.08 \mathrm{abc}$ & $0.76 \pm 0.05 \mathrm{abc}$ & $0.87 \pm 0.04 \mathrm{a}$ \\
\hline $40 \%$ & $0.81 \pm 0.06 \mathrm{ab}$ & $0.76 \pm 0.04 \mathrm{bc}$ & $0.80 \pm 0.04 \mathrm{ab}$ \\
\hline
\end{tabular}


Table 5

Results of one-way ANOVA showing the effects of water exchange rate (WER) on aggressivity (Av) values for total biomass in these two competing systems.

\begin{tabular}{|lllll|}
\hline & WER & \multicolumn{4}{l}{ Density ratio of Vallisneria natans. Myriophyllum species } \\
\cline { 3 - 5 } & & $\mathbf{6 : 2}$ & $\mathbf{4 : 4}$ & $\mathbf{2 : 6}$ \\
\hline V. natans - M. aquaticum system & 0 & $0.16 \pm 0.06 \mathrm{a}$ & $0.01 \pm 0.08 \mathrm{bc}$ & $-0.09 \pm 0.01 \mathrm{~d}$ \\
& $20 \%$ & $0.04 \pm 0.04 \mathrm{~b}$ & $-0.01 \pm 0.07 \mathrm{bc}$ & $-0.07 \pm 0.02 \mathrm{~cd}$ \\
\hline V. natans - M. spicatum system & 0 & $0.12 \pm 0.06 \mathrm{a}$ & $0.01 \pm 0.09 \mathrm{bc}$ & $-0.13 \pm 0.03 \mathrm{~d}$ \\
& $40 \%$ & $0.04 \pm 0.02 \mathrm{~b}$ & $-0.04 \pm 0.02 \mathrm{bcd}$ & $-0.07 \pm 0.03 \mathrm{~cd}$ \\
\hline & $20 \%$ & $0.10 \pm 0.05 \mathrm{ab}$ & $-0.03 \pm 0.04 \mathrm{~cd}$ & $-0.14 \pm 0.04 \mathrm{~d}$ \\
\hline $40 \%$ & $0.12 \pm 0.06 \mathrm{a}$ & $0.01 \pm 0.06 \mathrm{abc}$ & $-0.09 \pm 0.03 \mathrm{dcd}$ \\
\hline
\end{tabular}

Lower $A_{v}$ values were generally positively associated with lower values of root length $\left(R^{2}>0.30\right.$ and $P<$ 0.001 in $V$. natans - $M$. aquaticum system, but $R^{2}>0.08$ and $P=0.053$ in $V$. natans $-M$. spicatum system), $\operatorname{SRL}\left(R^{2}>0.27 ; P<0.001\right)$, plant $C$ content $\left(R^{2}>0.08\right.$ and $P=0.054$ in $V$. natans $-M$. aquaticum system, but $R^{2}>0.33 ; P<0.001$ in $V$. natans $-M$. spicatum system), and plant $\mathrm{P}$ content $\left(R^{2}>0.50\right.$ and $P<0.001$ in $V$. natans - $M$. aquaticum system, but $R^{2}>0.06 ; P=0.091$ in $V$. natans $-M$. spicatum system), but negatively associated with higher the values of root diameter $\left(R^{2}>0.15 ; P \leq 0.01\right)$ and $\mathrm{B}$ :A ratio $\left(R^{2}>0.16\right.$; $P=0.006$ ) (Figures S11-S14).

\section{Discussion}

Despite accumulating evidence of interspecific differences in functional traits in plants subjected to WER (Yuan et al., 2018; Pan et al., 2019), it remains unknown whether such differences can consequently alter the outcome of interspecies competition. Here, we examined the potential effects of WER on interactions between coexisting submerged macrophytes, and the links between relative competitive ability and functional traits in these species. Our results suggest that WER is an important factor driving plant competition, and shifts in relative competitive ability in response to WER and combination mode are directly attributable to consistently increasing the differences in functional traits between co-cultured species. Thus, our results show more support for the CTH hypothesis than CTS hypothesis. To the best of our knowledge, this is the first study to validate the CTH hypothesis by evaluating interspecies competition among aquatic macrophytes.

\section{Environmental variation in response to WER}

In the experiment without added ramets, DO concentration was consistently higher than $6.0 \mathrm{mg} \mathrm{L}^{-1}$ and within the range of those observed in the natural environments (Zhu et al., 2017, Tong et al., 2019; 
Ishikawa et al., 2019). DCD concentration consistently decreased as WER increased through the whole experiment (Fig. 1), and was always $<490$ ppm (minimum: 361 ppm), lower than the values reported in other indoor and field studies where $V$. natans found (Cao \& Ruan, 2015). DCD is among the principle sources of $C$ for the photosynthesis of submerged macrophytes (Dülger et al., 2017). Thus, DCD concentration may be the main factor limiting normal growth in the submerged macrophytes of our experimental system (Fig. 2), as revealed by the significant linear relationships between DCD concentration with plant biomass accumulation and height, regardless of species and competition system (Figure S2).

In aquatic ecosystems, DCD availability is influenced by the diffusion rate of $\mathrm{CO}_{2}$ across the air-water interface, its concentration difference between inflow and outflow water, the destruction of sediment organic matter, and photosynthetic uptake of DCD by primary producers (Marotta et al., 2010; Dülger et al., 2017). Given that this additional experiment was conducted in the absence of aquatic macrophytes, and that organic matter content showed no significant difference across all treatment sediments prior to the start of the experiment, the decrease in DCD concentration is likely attributable to increasing WER. DCD released by the microbial decomposition of sediment organic matter is carried away by outlet water (Hopkin et al., 1993), and the $\mathrm{CO}_{2}$ diffusion from water to air is accelerated by increased flow turbulence along with increasing WER (Jirka et al., 2010), particularly in the present study, because DCD concentration was significantly lower in incoming water than in bucket water (Table S1).

\section{Responses of plant functional traits to WER}

Optimal partitioning theory states that plants usually allocate biomass to the organ that acquires the most limiting resource to enhance fitness (Bloom et al., 1985). Thus, in our experimental system, DCD should be the factor limiting normal growth of submerged macrophytes. Leaf growth can promote the absorption of both DCD and DO, and the allocation of more biomass to stems benefits plant growth near or above the water surface where they can acquire more DCD and DO (Murillo et al., 2019; Li et al., 2020). Therefore, as WER increased, more biomass was allocated to above-ground tissues (leaves and stems) in two Myriophyllum species (Fig. 3), which is consistent with the findings of previous studies of plant adjustment strategies to DCD and/or DO deficiency (e.g., Yuan et al., 2018).

However, this strategy will inhibit root growth, which is the main factor influencing the absorption of environmental nutrients (Xie et al., 2007). Under such condition, the regulation of root morphology allows plants to efficiently increase nutrient absorption ability by developing longer and/or thinner roots (see Xie et al., 2007; Pan et al., 2012; Pan et al., 2014). Consistently, in this study, roots were longer and thinner and SRL was higher in higher-WER than in lower-WER treatments for two Myriophyllum species, regardless of the planting proportion of each species (Fig. 4). Through these adjustments, the nutrient absorption ability of the Myriophyllum species was not inhibited by reduced below-ground biomass, as revealed by gradually increased concentrations of plant N and P as WER increased (Fig. 5). The growth and development of submerged macrophytes is directly dependent on the rapid accumulation of elements, particularly $\mathrm{N}$ and $\mathrm{P}$, which are essential for the formation of various fundamental metabolites 
(Van de Waal et al., 2010). These results indicate that Myriophyllum species adapted well to WER variation through functional trait plasticity.

By contrast, biomass allocation and root morphological adjustments of $V$. natans showed opposite patterns to WER compared with Myriophyllum species. As WER increased, more $V$. natans biomass was allocated to below-ground part and to the production of new ramets. Roots of this species became shorter and thicker, and SRL generally decreased as WER increased, regardless of the planting proportion of each species. These responses will undoubtedly inhibit the absorption of both DCD and sediment nutrients. As predicted, $\mathrm{P}$ concentration of $V$. natans exhibited a decreasing trend with increasing WER, further demonstrating the important role of root morphology in determining nutrient absorption ability (Fig. 5).

Additionally, by using the replacement series experiment, we clearly showed that combination mode also induced trait divergence. As the planting proportion of $V$. natans decreased, B:A biomass ratio and root diameter increased, root length and SRL decreased, and plant nutrient generally decreased in $V$. natans; whereas the opposite trends were observed in co-cultured Myriophyllum species, regardless of the competition system. Besides, branch number per plant biomass significantly increased in $V$. natans, but exhibited no significant different in Myriophyllum species under the same conditions.

Clearly, both WER variation and combination mode induced species-specific changes in functional values between co-cultured submerged macrophytes. These trait divergences are reported to further affect species interactions (Callaway et al., 2003; Coomes \& Grubb, 2003; Fort et al., 2014), particularly interspecies competition, if interspecific differences are large (Pan et al., 2019). In the present study, $V$. natans was a stronger competitor than Myriophyllum species in static waterbodies, regardless of planting proportion of each species. However, the relative competitive ability of Myriophyllum species consistently increased with increasing WER and decreasing its planting proportion, which would eventually transform it into a strong competitor (Tables 3-5). Similarly, previous studies have demonstrated that Myriophyllum species are usually less competitive than other submerged macrophytes in stable water bodies (Wang et al., 2008). Given that competitive interaction resulted in decreases in trait similarity in interacting plants, we concluded that CTH played a more important role than CTS in determining relative abundance of plants.

\section{Conclusion}

The results of this study provided insight into the mechanism by which WER affects interspecific interaction between submerged macrophytes. Variation in relative competitive ability between co-cultured species was strongly associated with hierarchical differences in plant functional traits associated with DCD and nutrients acquisition, providing more support for the CTH hypothesis than CTS hypothesis.

Understanding interactions between competing individuals under WER variation is important for explaining plant distribution pattern and predicting further changes in plant communities of submerged macrophytes. For example, the present results will contribute to understanding the potential mechanisms 
driving Myriophyllum species distribution patterns in natural aquatic ecosystems, such as in tunnels and lakeshores, which are usually characterized by strong water exchange. Besides, $M$. aquaticum, a common indigenous species in South America, is now widespread in many countries, where it is considered a troublesome invasive (Orchard, 1981). In Yunnan Plateau lakes, invasive M. aquaticum successfully outcompetes native macrophytes. Our results provide insight into the establishment and spread of invasive $M$. aquaticum worldwide, due to the greater efficiency of its functional traits in terms of WER variation and nutrient deficiency tolerance compared to other submerged macrophytes (e.g., $V$. natans in the present study).

\section{Declarations}

\section{LANGUAGE EDITING}

The English in this document has been checked by at least two professional editors, both native speakers of English. For a certificate, please see:

http://www.textcheck.com/certificate/czXwwq

\section{ACKNOWLEDGEMENTS}

We are grateful to Chenxin Jin and Chuangyu Che for assistance in the experiment. This research was financially supported by the National Natural Science Foundation of China (Grant numbers 32071537, U2002208, 31670440, and 31660169), Key Project of Applied Basic Research Program of Yunnan Province, China (202001BB050021), and the Undergraduate Innovation and Entrepreneurship Training Program of China (202010673169).

\section{Author Contributions}

Ying Pan: designed the experiments, Writing - original draft, Formal analysis. Duanyang Yuan: Writing and methodology. Qihang Wu: Methodology. Ling Jin: Methodology. Mingli Xie: Methodology. Yang Gu: Methodology. Changqun Duan: Methodology.

\section{Competing financial interests}

The authors declare no competing financial interests.

\section{Additional information}

This manuscript has not been published or presented elsewhere in part or in entirety and is not under consideration by another journal. All authors have read and approved the manuscript. In addition, this study did not involve endangered or protected species, therefore, no specific permits were required.

\section{References}


Bloom, A.J., Chapin, F.S., Mooney, H.A., 1985. Resource limitation in plants-an economic analogy. Annual Review of Ecology and Systematics 16, 363-392. https://doi.org/10.1146/annurev.es.16.110185.002051

Burnett, S.A., Mealor, B.A., 2008. Imazapic Effects on Competition Dynamics Between Native Perennial Grasses and Downy Brome (Bromus tectorum). Invasive Plant Science \& Management, 8(1):72-80. https://doi.org/10.1614/IPSM-D-14-00032.1

Bi, H., Turvey, N.D., 1994. Inter-specific competition between seedlings of Pinus radiata, Eucalyptus regnans and Acacia melanoxylon. Australian Journal of Botany 42, 61-70.

https://doi.org/10.1071/BT9940061

Callaway, R., Pennings, S., Richards, C., 2003. Phenotypic plasticity and nteractions among plants. Ecology 84, 1115-1128. https://doi.org/10.1890/0012-9658(2003)084[1115:PPAIAP]2.0.C0;2

Cahill, J.F., Kembel, S.W., Lamb, E.G., Keddy, P.A., 2008. Does phylogenetic relatedness influence the strength of competition among vascular plants? Perspectives in Plant Ecology. Evolution and Systematics 10, 41-50. https://doi.org/10.1016/j.ppees.2007.10.001

Cao, J.J., Ruan, H.H., 2015. Responses of the submerged macrophyte Vallisneria natans to elevated $\mathrm{CO}_{2}$ and temperature. Aquatic Biology 23, 119-127. https://doi.org/ 10.3354/ab00605

Cao, T., Ni, L.Y., Xie, P., Xu, J., Zhang, M., 2011. Effects of moderate ammonium enrichment on three submersed macrophytes under contrasting light availability. Freshwater biology 56, 16201629.https://doi.org/10.1111/j.1365-2427.2011.02601.x

Connolly, J., 1986. On difficulties with replacement-serie methodology in mixture experiments. The Journal of Applied Ecology 23, 125-137. https://doi.org/10.2307/2403086

Coomes, D.A., Grubb, P.J., 2003. Colonization, tolerance, competition and seed-size variation within functional groups. Trends in Ecology \& Evolution 18, 283-291. https://doi.org/0.1016/S01695347(03)00072-7

De Wit, C.T., 1960. On competition. Verslagen van Landbouwkundige Onderzoekingen 66, 1-82.

Dhima, K., Lithourgidis, A., Vasilakoglou, I., Dordas, C., 2007. Competition indices of common vetch and cereal intercrops in two seeding ratios. Field Crops Research 100, 249-256.

https://doi.org/10.1016/j.fcr.2006.07.008

Dülger, E., Heidbüchel, P., Schumann, T., Mettler-Altmann, T., Hussner, A., 2017. Interactive effects of nitrate concentrations and carbon dioxide on the stoichiometry, biomass allocation and growth rate of submerged aquatic plants. Freshwater Biology 62, 1094-1104. https://doi.org/10.1016/j.fcr.2006.07.008

Fort, F., Cruz, P., Jouany, C., 2014. Hierarchy of root functional trait values and plasticity drive early-stage competition for water and phosphorus among grasses. Functional Ecology 28, 1030-1040. 
Gibson, D.J., Connolly, J., Hartnett, D.C., Weidenhamer, J.D., 1999. Designs for greenhouse studies of interactions between plants. The Journal of Ecology 87, 1-16. https://doi.org/10.1046/j.13652745.1999.00321.x

Good, C., Davidson, J., Welsh, C., Brazil, B., Snekvik, K., Summerfelt, S., 2009. The impact of water exchange rate on the health and performance of rainbow trout Oncorhynchus mykiss in water recirculation aquaculture systems. Aquaculture 294, 80-85.

https://doi.org/10.1016/j.aquaculture.2009.05.014

Goldberg, D., Novoplansky, A., 1997. On the relative importance of competition in unproductive environments. Journal of Ecology 85, 409-418. https://doi.org/10.2307/2960565

Grime, JP., 1977. Evidence for the existence of three primary strategies in plants and its relevance to ecological theory. American Naturalist 111, 1169-1194. https://doi.org/10.1086/283244

Hessen, D.O., Håll, J.P., Thrane, J.E., Andersen, T., 2017. Coupling dissolved organic carbon, $\mathrm{CO}_{2}$ and productivity in boreal lakes. Freshwater Biology, 1-9. https://doi.org/10.1111/fwb.12914

Hussner, A., Mettler-Altmann, T., Weber, A.P.M., Sand-Jensen, K., 2016. Acclimation of photosynthesis to supersaturated $\mathrm{CO}_{2}$ in aquatic plant bicarbonate users. Freshwater Biology 61, 1720-1732. https://doi.org/10.1111/fwb.12812

Hopkins, J.S., Hamilton, R.D., Sandier, P.A., Browdy, C.L., Stokes, A.D., 1993. Effect of water exchange rate on production, water quality, effluent characteristics and nitrogen budgets of intensive shrimp ponds. Journal of the World Aquaculture Society 24, 304-320. https://doi.org/10.1111/j.17497345.1993.tb00162.x.

Ishikawa, K., Haga, H., Inoue, E., Ban, S., 2019. Determining suitable submerged macrophyte biomass in terms of dissolved oxygen concentration and biodiversity in the South Basin of Lake Biwa, Japan. Limnology 20, 69-82. https://doi.org/10.1007/s10201-018-0566-y

Jirka, G.H., Herlina, H., Niepelt, A., 2010. Gas transfer at the air-water interface: experiments with different turbulence forcing mechanisms. Experiments in Fluids 49, 319-327. https://doi.org/10.1007/s00348010-0874-4

Tong, X.N., Wang, X.Z., Li, Z.K., Yang, P.P., Zhao, M., Xu, K.Q., 2019. Trend analysis and modeling of nutrient concentrations in a preliminary eutrophic lake in China. Environmental Monitoring and Assessment 191, 365. https://doi.org/10.1007/s10661-019-7394-3

Kraft, N.J.B, Godoy, O., Levine, J.M., 2015. Plant functional traits and the multidimensional nature of species coexistence. Proceedings of the National Academy of Sciences 112, 797-802. https://doi.org/ 
Kunstler, G., Lavergne, S., Courbaud, B., Thuiller, W., Vieilledent, G., Zimmermann, N.E., Kattge, J., Coomes, D.A., 2012. Competitive interactions between forest trees are driven by species' trait hierarchy, not phylogenetic or functional similarity: implications for forest community assembly. Ecology Letters 15, 831-840. https://doi.org/10.1111/j.1461-0248.2012.01803.x

Li, L., Ding, M., Jeppesen, E., 2020. Variation in growth, reproduction, and resource allocation in an aquatic plant, Vallisneria spinulosa: the influence of amplitude and frequency of water level fluctuations. Aquatic Science 82, 81. https://doi.org/10.1007/s00027-020-00754-8

Lu, R., 2000. Analytical methods for soil and agricultural chemistry (In Chinese). China Agricultural Science and Technology Press, Beijing.

Marotta, H., Duarte, C.M., Meirelles-Pereira, F., Bento, L., Esteves, F.A., Enrich-Prast, A., 2010. Long-term $\mathrm{CO}_{2}$ variability in two shallow tropical lakes experiencing episodic eutrophication and acidification events. Ecosystems 13, 382-392. https://doi.org/10.1007/s10021-010-9325-6

Murillo, R.A., Alves, D.C., Machado, R.S., Silveira, M.J., Rodrigues, K.F., Thomaz, SM., 2019. Responses of two macrophytes of the genus Polygonum to water level fluctuations and interspecific competition. Aquatic Botany 157, 10-16. https://doi.org/10.1016/j.aquabot.2019.05.003

Orchard, A.E., 1981. A revision of south american Myriophyllum (Haloragaceae), and its repercussions on some Australian and North American Species. Brunonia 4, 27-65. https://doi.org/10.1071/bru9810027

Pan, Y., Xie, Y.H., Chen, X.S., Li, F., 2012. Effects of flooding and sedimentation on the growth and physiology of two emergent macrophytes from Dongting Lake wetlands. Aquatic Botany 100, 35-40. https://doi.org/10.1016/j.aquabot.2012.03.008

Pan, Y., Xie, Y.H., Deng, Z.M., Tang, Y., Pan, D.D., 2014. High water level impedes the adaptation of Polygonum hydropiper to deep burial: responses of biomass allocation and root morphology. Scientific Reports 4, 5612. https://doi.org/10.1038/srep05612

Pan, Y., Jin, L., Wei, Z.H., Yang, S.K., Qian, L., Liu, C.E., Duan, C.Q., Sun, S.C., 2019. Experimental evidence that water-exchange unevenness affects individual characteristics of two wetland macrophytes Phalaris arundinacea and Polygonum hydropiper. Ecological Indicators 107, 105617. https://doi.org/10.1016/j.ecolind.2019.105617

Pires, A.P.F., Marino, N.A.C., Srivastava, D.S., Farjalla, V.F., 2016. Predicted rainfall changes disrupt trophic interactions in a tropical aquatic ecosystem. Ecology 97, 2750-2759. https://doi.org/10.1002/ecy.1501

Reitsema, R.E., Preiner, S., Meire, P., Hein, T., Boeck, G.D., Blust, R., Schoelynck, J., 2020. Implications of climate change for submerged macrophytes: effects of $\mathrm{CO}_{2}$, flow velocity and nutrient concentration on 
Berula erecta. Aquatic Ecology.https://doi.org/10.1007/s10452-020-09776-8

Tilman, D., 1980. Resources: A graphical-mechanistic approach to competition and predation. American Naturalist 116, 362-393. https://doi.org/10.2307/2463311

Van de Waal, D.B., Verschoor, A.M., Verspagen, J.M.H., van Donk, E., Huisman, J., 2010. Climate-driven changes in the ecological stoichiometry of aquatic ecosystems. Frontiers in Ecology \& the Environment 8(3), 145-152. https://doi.org/10.2307/20696462

Wersal, R.M., Madsen, J.D., 2011. Comparative effects of water level variations on growth characteristics of Myriophyllum aquaticum. Weed Research 51, 386-393. https://doi.org/10.1111/j.13653180.2011.00854.x

Wang, P., Stieglitz, T., Zhou, D.W., Jr, J.F.C., 2010. Are competitive effect and response two sides of the same coin, or fundamentally different? Functional Ecology 24, 196-207. https://doi.org/10.1111/13652435.12217

Wang, J.W., Yu, D., Xiong, W., Han, Y.Q., 2008. Above- and belowground competition between two submersed macrophytes. Hydrobiologia 607, 113-122. https://doi.org/10.1007/s10750-008-9371-7

Willey, R.W., 1979. Intercropping its importance and research needs part 1. competition and yield advantages. Field Crops Abstracts 32, 1-10. http://krishikosh.egranth.ac.in/handle/1/2056350

Xie, Y.H., An, S.Q., Wu, B.F., 2005. Resource allocation in the submerged plant Vallisneria natans related to sediment type, rather than water-column nutrients. Freshwater Biology 50, 391-402.

https://doi.org/10.1111/j.1365-2427.2004.01327.x

Xie, Y.H., Luo, W.B., Ren, B., Li, F., 2007. Morphological and physiological responses to sediment type and light availability in roots of the submerged plant Myriophyllum spicatum. Annals of Botany 100(7), 1517-1523. https://doi.org/10.1093/aob/mcm236

You, W.H., Yu, D., Liu, C.H., Xie, D., Xiong, W., 2013. Clonal integration facilitates invasiveness of the alien aquatic plant Myriophyllum aquaticum L. under heterogeneous water availability. Hydrobiologia 718, 2739. https://doi.org/10.1007/s10750-013-1596-4

Yuan, D.Y., Meng, X.Y., Duan, C.Q., Wei, Z.H., Gao, W., Chang, J.J., Lv, X.J., Pan, Y., 2018. Effects of water exchange rate on morphological and physiological characteristics of two submerged macrophytes from Erhai Lake. Ecology and Evolution 2018, 1-11. https://doi.org/10.1002/ece3.4703

Zhang, Q., Xu, Y.S., Huang, L., Xue, W., Sun, G.Q., Zhang, M.X., Yu, F.H., 2014. Does mechanical disturbance affect the performance and species composition of submerged macrophyte communities? Scientific Reports 4, 4888. https://doi.org/10.1038/srep04888 
Zhu, G.R., Di, G.L., Zhang, M., Cao, T., Ni, L.Y., Fang, R.T., Yu, G.L., 2018a. Biomechanical response of a submerged, rosette-forming macrophyte to wave action in a eutrophic lake on the Yungui Plateau, China. Environmental Science \& Pollution Research 25, 34027-34045. https://doi.org/10.1007/s11356-018$3047-2$

Zhu, G., Li, W., Zhang, M., Ni, L.Y., Wang, S.R., 2012. Adaptation of submerged macrophytes to both water depth and flood intensity as revealed by their mechanical resistance. Hydrobiologia 696(1), 77-93. https://doi.org/10.1007/s10750-012-1185-y

Zhu, G.R., Yuan, C.B., Di, G.L., Zhang, M., Ni, L.Y., Cao, T., Fang, R.T., Wu, G.G., 2018b. Morphological and biomechanical response to eutrophication and hydrodynamic stresses. Science of the Total Environment 622-623, 421-435. https://doi.org/10.1016/j.scitotenv.2017.11.322

Zhu, M.S., Zhang, H.C., Chang, F.Q., Li, H.Y., Duan, L.Z., Meng, H.W., Bi, R.X., Lu, Z.M., 2017. The seasonal variations of the water Quality of Erhai during 2015-2016. Advances in Environmental Protection 7, 297308 (In Chinese with an English abstract). https://doi.org/10.12677/AEP.2017.74042

\section{Supplementary Files}

This is a list of supplementary files associated with this preprint. Click to download.

- 7Supplementaryfiles.docx 